* doi:10.4317/medoral.17643949

http://dx.doi.org/10.4317/medoral.17643949

Aims: To analyze and compare the "Educational Climate" (EC) of medical and dental students from the University of Santiago de Compostela (USC), using the DREEM questionnaire ("Dundee Ready Education Environment Measure").

Material and Methods: The study group consisted of 671 medical students and 110 dental students, who responded to the DREEM questionnaire during the 20142015 academic year. This questionnaire has 50 items that are grouped into 5 domains: "Learning", "Teachers", "Academic", "Atmosphere" and "Social". Taking into account the maximum scores for the different domains and for EC, the data are converted into percentages of the global scale or of their respective subscale. Broadly, a higher score means a perception that is more positive than negative in relation to the educational aspect being examined.

Results: The EC score in Medicine and Dentistry were 110,7 (55.0\%) and 116,5 (58.2\%) respectively. The scores obtained in both careers in the different domains were: $47.3 \%$ and $52.5 \%$ in "Learning", $51.6 \%$ and $55.9 \%$ in "Teachers", 60.2\% and 61.9\% in "Academic", 56.2\% and $60.2 \%$ in "Atmosphere" and $59.1 \%$ and $62.5 \%$ in "Social". In 17 (34\%) and 12 items (24\%) respectively, an average $<2$ was detected.

Conclusions: USC students felt that their EC was more positive than negative, because the different domains were considered "positive and acceptable". Although the perception of the EC in Dentistry was significantly better, in both university degrees the students identified a considerable number of problematic educational aspects.

\section{- Oral Presentation 60}

TITLE: The use of the CBCT in the geriatric patient to control large apical lesions. Apropos of a case

AUThORS: Ruiz Piñón M, Martin Cruces J, Castelo Baz P.

Master of Endodontics. University of Santiago de Compostela.

SOURCE: Med Oral Patol Oral Cir Bucal. 2015

June 1;20(Supplement1):S24.

* doi:10.4317/medoral.17643950

http://dx.doi.org/10.4317/medoral.17643950

Introduction: Geriatric patients have a healing and bone regeneration lower than young patients. The use of CBCT technology allows us to test the healing process in these patients with a low dose of radiation.

Case Report: 69 year old male patient referred to our office for endodontic teeth 11 and 13 and later perform a surgery at the apical region of a 12 chronic apical periodontitis and presented no previous endodontic treatment.

After talking with the patient and the dentist who referred, we decided to perform endodontic treatment in order to try to reduce the size of the apical lesion because we supposed an endodontic origin of the injury (was more than $2 \mathrm{~cm}$ ) and affected maxillary sinus, nasal cavity with bone destruction.

After performing a root canal using ProTaper and obtured with Thermafil, radiographs and CBCT system control is performed annually, 2.34 and 6 below.

Conclusions: The lesion was reduced almost entirely, although healing has been slow due in part to the patient's age. The CBCT is an excellent method to evaluate and control the size reduction in this type of apical lesions.

\section{- Oral Presentation 61}

TITLE: Oral health and quality of life at the senior citizen's social clubs for people aged 65 and over in Valencia. Preliminary study

\section{AUTHORS: Sáez Prado B, Haya Fernández MC, Sanz García MT.}

Universidad Cardenal Herrera CEU, Valencia.

SOURCE: Med Oral Patol Oral Cir Bucal. 2015

June 1;20(Supplement1):S24.

* doi:10.4317/medoral.17643951
http://dx.doi.org/10.4317/medoral.17643951

Aim: The aim of this survey was to investigate if there is a relationship between the oral health status and the oral and general health related quality of life of elderly people aged 65 years or more in Valencia, Spain, through a preliminary study.

Methods: We designed a cross-sectional oral health survey plus an oral examination in an elderly population. Subjects: 48 adults (22 men and 26 women). Age: 65 years of age and over. Setting: Randomly selected senior citizen's social clubs. We assessed the Oral Health Impact Profile (OHIP-14) and a general health-related quality of life instrument: the EuroQol-5d with a visual analogue scale (VAS). We also inquired sociodemographic and oral health questions.

Results: The mean additive score of the OHIP-14 was 10.48 , the mean value of the EuroQol-5d was 0.56 and of the VAS, 70.33. We found no relationship between Euro-QoL5D and OHIP-14. Neither there were relation between these instruments and variables as decayed teeth or absences. On the other hand the OHIP-14 was consistently and significantly correlated with the oral 
Hygiene (brushing, toothpaste) and the dental status (being or not edentulous).

Conclusions: The oral health has a high impact on quality of life. The oral quality of life does not seem to be related to the general quality of life. The oral hygiene and getting toothless influence negatively on the quality of life of elderly population.

\section{- Oral Presentation 62}

TITLE: Complications in prosthetic rehabilitations on implants: a retrospective observational clinical study

AUTHORS: Sanz Sánchez A, Linares Bódalo S, Buesa Bárez JM, Fernández Cáliz F, Santos Marino J.

Master en Cirugía Bucal e Implantología. Hospital Virgen de la Paloma.

SOURCE: Med Oral Patol Oral Cir Bucal. 2015

June 1;20(Supplement1):S25.

* doi:10.4317/medoral.17643952

http://dx.doi.org/10.4317/medoral.17643952

Objectives: analyze the complications in prosthesis on implants in patients rehabilitated at the Oral surgery and implantology master from Hospital Virgen de la Paloma, as well as to establish the percentage of these depending on the type of prosthesis and the time elapsed since its placement.

Material and Methods: An observational retrospective clinical study was carried out on a total of 284 stories, in which the following variables were evaluated: epidemiological data, elapsed time, type of prosthesis and complication. The results were submitted to descriptive and inferential statistical treatment using the SPSS 21.0 system for Mac OC X.

Results: 284 stories were reviewed among which, 64 patients were found with complications in their prosthetic rehabilitación on implants. The average age was 69 , $2 \pm 11,19$ years old. The most used prosthesis was fixed (65.6\%). The main complication $(40.6 \%)$ was related to prosthetic attachments, however, no statistically significant difference was found between the types of prostheses, and complications. The average elapsed time from the placement of the prosthesis until the complication appears was $21,41 \pm 34,38$ months.

Conclusions: Complications on implants rehabilitations frequently affect prosthetic attachments. Therefore, it is necessary the maintenance of prosthetic rehabilitations every 6-12 months to avoid complications and to assess the condition of the periimplant tissue.

\section{- Oral Presentation 63 \\ TITLE: Ulcerative oral lesion on a leukoplakia.} A case report

\author{
AUTHORS: Schemel Suárez M, Dávila Monzón C, \\ López López J, Jané Salas E. \\ Facultad de Odontología, Universidad de Barcelona. \\ SOURCE: Med Oral Patol Oral Cir Bucal. 2015 \\ June 1;20(Supplement1):S25. \\ * doi:10.4317/medoral.17643953 \\ http://dx.doi.org/10.4317/medoral.17643953
}

Introduction: Oral ulcers are very frequent and have a diverse etiology (infectious factors, trauma, neoplasia, multiple syndromes, among others). The most common cause of oral ulcers is trauma, and the treatment in this cases is the removal of the traumatic agent (sharp teeth, inadequate dental prosthesis, etc.), but when a lesion does not resolve in a 2 week period after the removal of the traumatic agent, the diagnosis will be confirmed with a biopsy, because it could be a process that needs a more complex treatment.

Case report: A 65 year old woman with a medical history of OSCC in the upper left maxilla, on a lesion years before diagnose as an oral lichen planus, attends the dental clinic for evaluation. Intraoral examination revealed an ulcer on a non-removable white plaque in the left lateral border of the tongue. Because of the patient's medical history, a biopsy and histological study was performed. The result rules out a malignant lesion but indicates the presence of viral inclusions.

Conclusions: A periodic dental evaluation is very important, especially in patients that are on chronic treatment with topical or systemic corticosteroids since the immunosuppressive action of this drug can produce oral lesions that sometimes can mimic malignant pathologies.

\section{- Oral Presentation 64 TITLE: Oral Cancer: Risk factors in elderly. An update}

AUTHORS: Schiavo Di Flaviano V. Martin C. Somacarrera ML.

Facultad de Ciencias Biomédicas. Departamento de Odontología. Universidad Europea de Madrid.

SOURCE: Med Oral Patol Oral Cir Bucal. 2015 June 1;20(Supplement1):S25.

* doi:10.4317/medoral.17643954

http://dx.doi.org/10.4317/medoral.17643954

Objective: Oral cancer is a prevalent disease in the elderly. It is estimated to claim about 1117 lives a year in 